\title{
Derechos humanos y activismo legal transnacional. Estrategias de las ONG en México y Colombia
}

\author{
Jairo Antonio López Pacheco, ${ }^{*}$ Sandra Hincapié Jiménez ${ }^{* *}$
}

Perfiles Latinoamericanos

Flacso México

\section{Resumen}

Este artículo analiza el activismo legal transnacional en defensa de los derechos humanos que las organizaciones no gubernamentales realizan en Colombia y México. A partir de una metodología comparada argumentamos que las estrategias de articulación y coordinación de los actores colectivos en el plano nacional representan un factor determinante para el éxito en la presión transnacional en materia de derechos humanos; hemos identificado dos patrones de actuación diferenciada: una estrategia de concentración-coordinación de demandas en el caso colombiano, y una estrategia de segmentación-fragmentación de las demandas en el caso mexicano.

\begin{abstract}
This article analyzes the transnational legal activism of human rights NGOs in Colombia and Mexico. From a comparative methodology argue that successful transnational pressure on human rights has a determining factor in the coordination strategies of collective actors at the national level. We identified two distinct patterns of action: first, a concentration-coordination strategy of demands in the Colombian case, second a segmentation-fragmentation strategy of demands in the Mexican case.
\end{abstract}

Palabras clave: activismo transnacional, derechos humanos, organizaciones no gubernamentales, sistema interamericano de derechos humanos.

Keywords: Transnational activism, human rights, non-governmental organizations, inter-American human rights system.

* Doctor de Investigación en Ciencias Sociales por la Flacso México. Profesor investigador, Unidad Académica de Ciencia Política de la Universidad Autónoma de Zacatecas.

** Doctora de Investigación en Ciencias Sociales por la Flacso México. Profesora investigadora, Unidad Académica de Ciencia Política de la Universidad Autónoma de Zacatecas. 


\section{Introducción}

ntensos debates sobre impunidad y castigo a los crímenes de lesa humanidad se están dando en Colombia en el marco de las negociaciones de paz entre el gobierno nacional y la guerrilla de las Fuerzas Armadas Revolucionarias de Colombia. Analistas, académicos, activistas, así como organismos y organizaciones nacionales e internacionales, se han pronunciado a favor del acuerdo de paz, subrayando la necesidad de que se esclarezcan las responsabilidades de todos los actores civiles y armados (estatales y no estatales) en los graves crímenes que contra la humanidad se han cometido durante el largo conflicto armado colombiano.

Por su parte, desde finales de 2014, y tanto a nivel nacional como internacional, se ha cuestionado al Estado mexicano sobre su compromiso con el respeto y garantía de los derechos humanos. En el plano nacional, una intensa acción colectiva de diversos sectores de la sociedad civil, entre las que se encuentran las organizaciones de derechos humanos, han puesto de relieve la indignación y la exigencia de respuestas gubernamentales efectivas por casos ya paradigmáticos como el de Ayotzinapa, donde las graves violaciones de derechos humanos fueron perpetradas presuntamente por el crimen organizado en connivencia con organizaciones estatales. A pesar de las demandas en las últimas décadas, por parte de organizaciones no gubernamentales (ONG) de derechos humanos, para que se reconozcan y garanticen las normas internacionales de derechos humanos en México, informes recientes han establecido que la impunidad es un rasgo característico y persistente del sistema de justicia mexicano, lo cual impide la efectiva realización y cumplimiento de los derechos humanos reconocidos constitucionalmente (Comisión Interamericana de Derechos Humanos, 2015).

Ante esta situación de impunidad en el plano nacional, tanto en México como en Colombia y en toda América Latina, las ONG de derechos humanos, en años recientes y para sus respectivos países, han recurrido al sistema interamericano de derechos humanos como escenario de demanda y movilización para presionar por un mayor respeto de los derechos humanos. Esto ha sido posible por el desarrollo de los mecanismos internacionales de protección de derechos humanos, los cuales han puesto en cuestión las jurisdicciones de la soberanía estatal al reconocer a cada persona como sujeto de derecho de derecho internacional.

Hasta ahora son pocos los estudios que analizan el activismo legal transnacional de las ONG de derechos humanos en América Latina. En este artículo emprendemos un estudio comparado de la acción colectiva de las organizaciones 
de derechos humanos en Colombia y México ante el sistema interamericano de derechos humanos, aportando así información novedosa sobre las estrategias de movilización e interacción frente a los organismos internacionales. ${ }^{1}$ Argumentamos que el éxito en la presión transnacional en materia de derechos humanos encuentra un factor determinante en las estrategias de articulación de los actores colectivos en el plano nacional, en ese sentido, identificamos dos patrones de actuación diferenciada de dicho activismo legal transnacional: primero, una estrategia de concentración-coordinación de demandas en el caso colombiano, segundo, una estrategia de segmentación-fragmentación de las demandas en el caso mexicano.

\section{El activismo legal transnacional y el sistema interamericano de derechos humanos}

El principio básico que guiaba al derecho internacional hasta bien entrado el siglo xx era la regulación de las relaciones entre Estados soberanos. Pero en las últimas décadas de ese mismo siglo ese principio fue socavado y cuestionado a través de la inclusión de los individuos en las provisiones del derecho internacional, al exigirles la necesaria observación de "una obligación moral que claramente trasciende su obligación como ciudadano de un Estado, abriendo de esa manera una brecha entre los derechos y deberes contenidos en la ciudadanía y la consagración en el derecho internacional de nuevas formas de libertades y obligaciones" (Held, 1997: p. 131). Así mismo, por la presión de diversos agentes internos y externos, los Estados cada vez más han adecuado su ordenamiento jurídico para incorporar derechos fundamentales reconocidos como universales (Ferrajoli, 2007), y han acometido reformas en las organizaciones estatales para que estas se ajusten a los tratados internacionales vigentes que exigen ciertas disposiciones para la protección de tales derechos (Hincapié, 2013: p. 35).

Actualmente existe un importante acumulado de investigaciones que estudian la acción de actores colectivos defensores de derechos humanos en "redes de presión trasnacional" que buscan incidir sobre los Estados y producir cambios de comportamiento que incorporen los principios de los derechos humanos

1 Toda la información que se presenta fue producto de la sistematización de los reportes anuales de la Comisión Interamericana de Derechos Humanos y la Corte Interamericana de Derechos Humanos, así como la revisión de contenidos de todas las sesiones realizadas sobre los casos de Colombia y México en la Comisión Interamericana de Derechos Humanos entre los ańos 1997 y 2013. Igualmente, se realizaron treinta entrevistas con líderes de organizaciones, funcionarios gubernamentales y expertos. 
en los marcos estatales (Risse, Ropp \& Sikkink, 2013, 1999; Simmons, 2009; Keck \& Sikkink, 2000). Esas investigaciones han analizado y explicado algunas estrategias de movilización, concentrándose en particular en la presión que se ejerce mediante lo que denominan "nombrar y avergonzar", lo cual consiste en socializar información con actores internacionales comprometidos con la política de derechos humanos esperando presionar así a los Estados violadores a fin de que estos cambien sus prácticas (Jetschke \& Liese, 2013; Anaya, 2012; Bob, 2010; Keck \& Sikkink, 2000).

Unida a la anterior estrategia, una de las tendencias crecientes en la acción colectiva de las ONG de derechos humanos es el activismo legal transnacional, el cual se refiere a las estrategias jurídicas que se efectúan ante instancias internacionales (tribunales u organismos cuasi judiciales) para que reconozcan las demandas de esas ONG y actúen en consecuencia sobre los Estados nacionales.

Hasta ahora es poca la investigación sobre el activismo legal transnacional como estrategia de acción colectiva llevada a cabo por las organizaciones de derechos humanos, este vacío en la literatura es en especial significativo en América Latina ya que el sistema interamericano de derechos humanos presenta un espacio de oportunidad relativamente abierto para la acción de ese tipo de organizaciones (MacDowell, 2007; Haddad, 2012). Los principales estudios existentes sobre el activismo legal en materia de derechos humanos se han enfocado en demostrar, de manera general, cómo la movilización del derecho y el lenguaje jurídico pueden resultar un "soporte" efectivo de demandas sociales o en los efectos judiciales de las sanciones obtenidas (Tsutsui, Whitlinger \& Lin, 2012; Ansolabehere, 2010; Garth, 2008; McCann, 2006; Sikkink, 2005).

No obstante, debe decirse que el activismo legal transnacional como estrategia de acción colectiva en la exigencia del respeto de los derechos humanos es una reciente práctica de actuación, lo que ayuda a explicar la ausencia de investigaciones al respecto. Esto es, solo hasta hace pocos ańos fue posible el fortalecimiento de los mecanismos del sistema interamericano de derechos humanos que permitiera hacer más efectiva su capacidad para ejercer la labor de protección de los derechos humanos en el continente. Mientras que, en el caso de los estudios referidos a Colombia y México, el crecimiento y consolidación de las organizaciones de derechos humanos ha sido un proceso de expansión apenas desarrollado en las dos últimas décadas.

Ahora bien, el sistema interamericano de protección de derechos humanos está compuesto por la Comisión Interamericana de Derechos Humanos (CIDH) y la Corte Interamericana de Derechos Humanos (Corte IDH), las cuales están sujetas a la Convención Americana sobre Derechos Humanos o Pacto de San José, suscrito el 22 de noviembre de 1968 y vigente desde junio de 1979. Los órganos del sistema interamericano fueron concebidos como "instancias 
excepcionales" a las que podían acudir las víctimas de violaciones de derechos humanos en caso tal que al interior de los Estados no se hicieran cumplir las sanciones o investigaciones judiciales (Cárdenas, 2007).

Por una parte, en el nivel cuasi jurisprudencial, la CIDH examina la incidencia en el comportamiento estatal por medio de la producción de informes especializados con contenidos de diagnóstico y evaluación que son de tipo anual, general, temático y especial. De igual forma, tiene la capacidad de admitir y tramitar casos de violaciones individuales, publicar informes con recomendaciones sobre los casos, decidir sobre su envío a la Corte IDH (para que esta se pronuncie judicialmente) y emitir medidas cautelares como acciones preventivas que pretenden evitar que se causen daños irreparables a las personas involucradas en los casos de denuncia mientras se desarrolla su análisis (González, 2010). Por otra parte, la Corte IDH como órgano jurisdiccional supranacional ha establecido diferentes clases de sentencias y pronunciamiento sobre los casos contenciosos que lleva adelante: las sentencias de excepciones preliminares, las de fondo, las de reparaciones y las de interpretación de fallo. Durante el trámite de estas sentencias, es decir, cuando la Corte IDH recibe y acepta un caso contencioso, también cuenta con la capacidad de emitir resoluciones de medidas provisionales o resoluciones de cumplimiento de sentencias, y todos sus fallos resultan vinculantes e inapelables (Jaramillo \& Castro, 2008).

Desde la creación de la CIDH las denuncias interpuestas por individuos u ONG han aumentado de forma constante. Tanto la CIDH como la Corte IDH se fortalecieron con las reformas a sus reglamentos en el año 2001, mismas que buscaron mejorar los procedimientos de las denuncias en cuanto a sus etapas, plazos y formas de participación, entre otras: "particularmente, con relación a la Corte, facilitaron el desarrollo y sustento de una jurisprudencia que brinda seguridad jurídica a las partes respecto del alcance y contenido de los derechos y de las obligaciones internacionales de los Estados en materia de derechos humanos" (Gallón, 2007: p. 53).

A partir del fortalecimiento de sus funciones, la CIDH aumentó sus actividades de protección de derechos humanos realizando más visitas in loco, con una dinámica de comunicados de prensa más activa, desarrollando trabajo de cooperación más cercano a las organizaciones de la sociedad civil y, principalmente, prestó más casos de demanda ante la Corte IDH. En este rubro, en 1997 y 1998 se presentaron dos y tres casos, respectivamente, ante la Corte IDH, con lo que se pasó a un promedio de catorce casos presentados entre 2003 y 2010, con el 2011 como el año con mayor número con un total de 23 (Comisión Interamericana de Derechos Humanos, 2012: p. 66).

$\mathrm{Al}$ construir bases de información con los datos proporcionados por la CIDH podemos identificar cómo, luego del fortalecimiento del sistema interamericano 
en 2001, México y Colombia son los dos países sobre los cuales se han presentado el mayor número de denuncias (gráfico 1). De esta tendencia, acentuada desde 2007, resaltan dos aspectos: por un lado, Colombia inició el siglo XXI con un promedio de aproximadamente cincuenta peticiones presentadas hasta 2003, pero un acelerado crecimiento de este rubro lo llevó a ser uno de los dos países con mayor cantidad de denuncias entre 2007 y 2013, esto es, durante el gobierno de Álvaro Uribe (2002-2010), un periodo caracterizado por una fuerte confrontación a la defensa de los derechos humanos (López Pacheco, 2013). Por otro lado, México ha sido uno de los países con mayor número de peticiones recibidas después de 2001, lo que aumentó desde 2010 en más de un cien por ciento; de esta forma, dicha nación alcanzó un alarmante indicador de más de seiscientas peticiones en 2013, lapso de tiempo marcado por la crisis de violencia y seguridad desatada tras la política de "guerra contra las drogas" del presidente Felipe Calderón (2006-2012).

A pesar de coincidir en los altos índices de denuncia, Colombia y México tienen resultados diferentes en informes de admisibilidad, como se observa en el gráfico 2. La admisibilidad de los casos significa que la CIDH los analizará, se pronunciará sobre los mismos y, dependiendo de su trámite, pueden llegar a presentarse ante la Corte IDH, es decir, son el camino necesario que deben seguir los casos para aspirar a un activismo legal transnacional exitoso.

De acuerdo a una muestra de 142 ong defensoras de derechos humanos que seleccionamos en ambos países, ${ }^{2}$ en Colombia se identificó un periodo determinante de formalización de la defensa de los derechos humanos entre 1982 y 1995 , cuando aparecieron aproximadamente el 25\% de este tipo de ONG hoy existentes. Por su parte, en México el punto más importante del mismo fenómeno se vivió en los años 1994-1995 y luego del 2000 (posterior a la alternancia política). Es un periodo en el que apareció mucho más del $50 \%$ de las organizaciones defensoras de derechos humanos (gráfico 3).

Más allá de la diferencia proporcional de ONG en los años ochenta y principios de los noventa en ambos países, en cada uno de los contextos nacionales los nacientes actores dieron forma a interacciones y prácticas que formalizaron las demandas por los derechos frente a los gobiernos.

2 La muestra seleccionada de 142 organizaciones en ambos casos se basó en tres criterios: $a$ ) las organizaciones se autodefinen como defensoras de derechos humanos y tienen en sus planes de acción cuestionar o presionar al gobierno por el cumplimiento de los derechos; $b$ ) organizaciones que tienen participación en el sistema interamericano de derechos humanos, $\mathrm{y} c$ ) organizaciones que firmaban los principales comunicados de demanda de las plataformas nacionales de derechos humanos. Con esta fuente de información clasificamos a las ONG por año de creación, tipo de acción, ubicación, área de influencia, orientación y principales estrategias. 
Gráfico 1. Peticiones presentadas ante la CIDH, 2000-2013

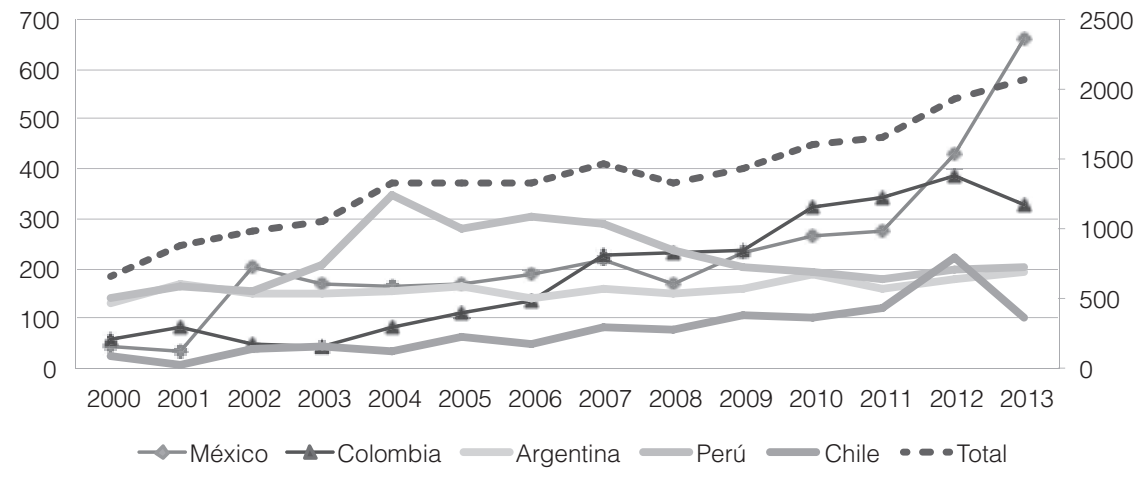

Fuente: Elaboración propia con datos de los informes anuales de la CIDH.

Gráfico 2. Informes de admisibilidad de México y Colombia en la CIDH, 1997-2013

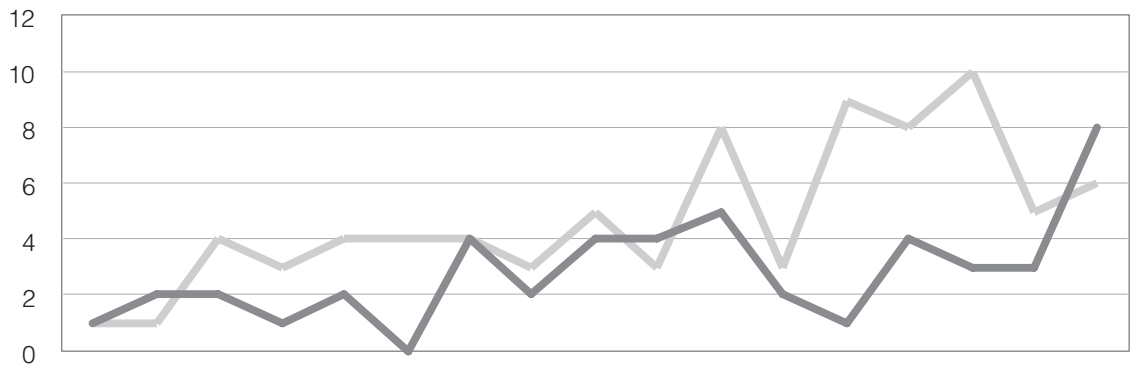

19971998199920002001200220032004200520062007200820092010201120122013

Informes de Admisibilidad de Colombia Informes de Admisibilidad de México

Fuente: Elaboración propia con datos de los informes anuales de la CIDH.

Gráfico 3. ONG defensoras de derechos humanos creadas en Colombia y México, 1982-2012

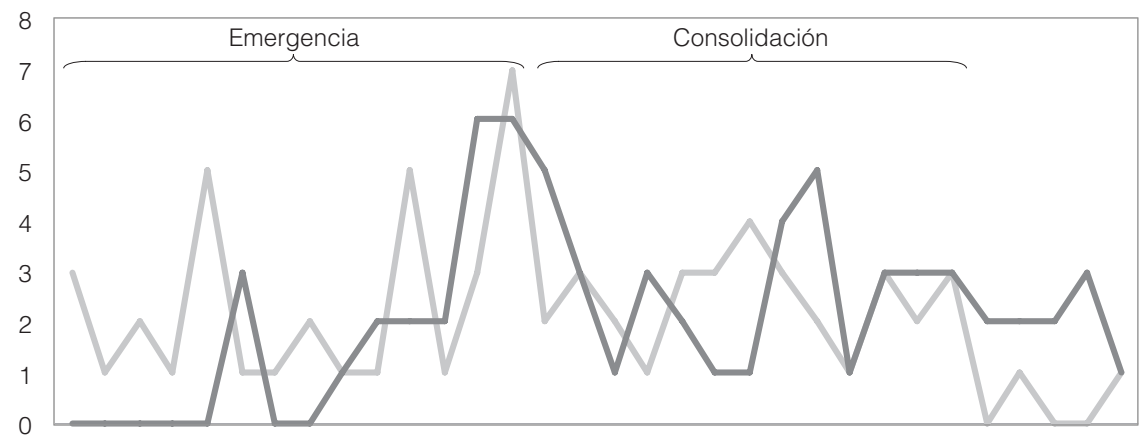

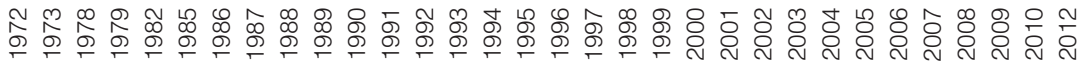

$$
\text { Colombia México }
$$

Fuente: Elaboración propia con datos de ONG activistas en Colombia y México. 
A partir de esta información, y dado nuestro interés por explicar la acción colectiva de las organizaciones de derechos humanos en sus estrategias de activismo legal transnacional, nos preguntamos: ¿cuáles son las estrategias seguidas por los actores no gubernamentales en el activismo legal transnacional?, ¿qué tipo de presencia en la defensa de los derechos humanos tienen las ONG como actores especializados ante el sistema interamericano de derechos humanos?, ¿cuál es la relación que las organizaciones establecen entre ellas para impulsar las demandas y convencer a los organismos internacionales de la situación de crisis de derechos humanos?

\section{Colombia: acción colectiva concentrada y coordinada}

Desde la creación en los años setenta y ochenta de las primeras ONG de derechos humanos en Colombia como el Centro de Investigación y Educación Popular (Cinep) (1972), la Fundación Comité de Solidaridad con los Presos Políticos (FCSPP) (1973) y el Comité Permanente para la Defensa de los Derechos Humanos (CPDDH) (1979), las ONG empezaron a estructurar diversas estrategias de acción colectiva como el activismo jurídico, la producción de información y conocimiento, la intervención en zonas de conflicto y la construcción de paz, siempre orientadas a la defensa de los principios constitucionalmente reconocidos y como alternativa política al conflicto armado (López, 2012).

Con su marco político y jurídico la Constitución de 1991 abrió una estructura de oportunidad para las ONG de derechos humanos, las que así experimentaron un proceso de expansión y especialización que les permitió apropiarse del horizonte de derechos al interior del Estado y ser mediadoras de la movilización social en todo el país (Tate, 2007; Romero, 2001). A partir de allí las organizaciones han mantenido plataformas de coordinación y cooperación como Plataforma Colombiana de Derechos Humanos, Democracia y Desarrollo, la Asamblea Permanente de la Sociedad Civil por la Paz, La Alianza y la Coordinación Colombia Europa Estados Unidos (CCEEU), cuya base se encuentra en las propuestas alternativas al conflicto armado y el desarrollo democrático en las regiones de Colombia (López, 2012).

Actores preponderantes: el desarrollo de la experticia

Las primeras ONG creadas específicamente para la defensa legal fueron el Comité de Solidaridad con los Presos Políticos, la Comisión Colombiana de Juristas (CCJ) (1988) y el Colectivo de Abogados José Alvear Restrepo (CAJAR) (1991). 
El primer hito del activismo legal transnacional fue el caso llevado ante la CIDH en marzo de 1992, por los sistemáticos actos de violación de derechos humanos (homicidios, desapariciones forzadas, torturas) ocurridas en el municipio de Trujillo entre finales de 1988 e inicios de 1990. Como parte de un acuerdo amistoso dentro del proceso se decidió integrar una Comisión de Investigación de los sucesos violentos de Trujillo, la cual produjo un Informe Final, que fue acogido de manera unánime por las partes y que hizo suya la CIDH, y donde se demostró la responsabilidad de agentes estatales en las violaciones y se establecieron distintas recomendaciones para el Estado colombiano (Comisión de Investigación de los Sucesos Violentos de Trujillo, 1995).

Después de la Resolución de la Comisión Interamericana de Derechos $\mathrm{Hu}-$ manos, el 31 de enero de 1995 el entonces presidente Ernesto Samper debió aceptar oficial y públicamente la responsabilidad del Estado por las violaciones de derechos humanos ocurridas durante el periodo; esta fue la primera vez en la historia de Colombia que un presidente reconocía responsabilidades estatales en actos de violación de derechos humanos (Ramírez, 2009; Tate, 2007: p. 55).

Tabla 1. Participación de las ONG en casos admitidos por la CIDH contra Colombia, 1997-2013

\begin{tabular}{lcc}
\hline ONG & Casos & $\%$ \\
\hline Colectivo de Abogados José Alvear Restrepo & 24 & 24.5 \\
Comisión Colombiana de Juristas & 15 & 15.3 \\
Demandas individuales & 13 & 13.3 \\
Grupo Interdisciplinario de Derechos Humanos & 12 & 12.2 \\
Organizaciones Internacionales (CEJIL, FEDEFAM) & 6 & 6.12 \\
Asociación de Familiares de Detenidos Desaparecidos & 4 & 4.08 \\
Comisión Intereclesial de Justicia y Paz & 4 & 4.08 \\
Particulares por el Grupo Jurídico de Antioquia & 4 & 4.08 \\
Humanidad Vigente & 3 & 3.06 \\
Asociación Minga & 3 & 3.06 \\
SIP & 3 & 3.06 \\
Fundación Comité de Solidaridad con los Presos Políticos & 1 & 1.02 \\
Fundación de Derechos Humanos "Joel Sierra" & 1 & 1.02 \\
Corporación Sembrar & 1 & 1.02 \\
Reiniciar & 1 & 1.02 \\
ANDAS & 1 & 1.02 \\
Asodebol & 1 & 1.02 \\
Corporación Jurídica Colombiana & 1 & 1.02 \\
Total & 100 \\
\hline
\end{tabular}

Nota: Un solo caso puede tener varias ONG como titulares de las demandas. En la tabla se consigna el número de veces que una ONG fue parte titular de un caso sin importar si actuó individualmente o con la compañía de otra.

Fuente: Elaboración propia con datos de Casos de la CIDH. 
A partir de 1995 se profundizó el proceso de especialización de las ONG dedicadas al activismo jurídico y con ellas la consolidación de estrategias de división del trabajo y cooperación para las demandas transnacionales.

Como se observa en la tabla 1, 16 ong han participado en casos aceptados ante la $\mathrm{CIDH}$, de estas el Colectivo de Abogados José Alvear Restrepo y la Comisión Colombiana de Juristas acumulan participación en aproximadamente $40 \%$ de los casos presentados y admitidos para su revisión. En la misma vía, organizaciones como el Grupo Interdisciplinario de Derechos Humanos (GIDH), Asociación de Familiares de Detenidos y Desaparecidos (ASFADDES), la Comisión Intereclesial de Justicia y Paz (CIJP), Humanidad Vigente y la Minga acumulan participación en $26 \%$ de las denuncias interpuestas y aceptadas.

Lo anterior evidencia una estrategia dirigida por las organizaciones a posicionar sus demandas dentro del activismo legal transnacional, un uso rutinario de la CIDH como espacio de presión por medio de actores especializados, así como la concentración de las demandas jurídicas transnacionales en las cinco principales organizaciones defensoras de derechos humanos especializadas en la defensa judicial.

\section{Presión en la CIDH: coordinación de la participación}

En el caso colombiano la articulación en red resultó fundamental para la cooperación e intercambio de la información ya que las ONG abocadas al activismo jurídico presentan sus casos contenciosos con base en la información recolectada sobre todo por las ONG dedicadas a la producción de información y conocimiento, las cuales se nutren de datos de casos de violación recogidos y documentados por organizaciones locales articuladas en redes. Un ejemplo de esto es el banco de datos Noche y Niebla del CINEP, el cual recoge sistemáticamente las violaciones de derechos humanos en Colombia (López, 2012: p. 114).

Debido a esta división de trabajo, las organizaciones especializadas en la producción de información y conocimiento son protagonistas en la construcción de cifras y en la elaboración de contextos de violación e información confiable para las demandas colectivas, habilidad que les ha sido reconocida internacionalmente. ${ }^{3}$ La capacidad de producir información confiable fue en especial importante durante los dos periodos de gobierno de Álvaro Uribe

3 En un reciente análisis comparado de Sandra Ley se reconoce que las ong de Colombia, Argentina y Guatemala han desarrollado altas capacidades en la producción de información sobre las violaciones a los derechos humanos puesto que llevan conteos confiables que permiten sustentar las acciones de órganos internacionales y las evaluaciones frente a los respectivos Estados (Ley, 2012). 
(2002-2010), cuando aconteció un intenso activismo legal transnacional que halló como respuesta una fuerte confrontación pública por parte del Ejecutivo (tabla 2). ${ }^{4}$

En la mayoría de las sesiones en las ONG participaron con la documentación producida por ellas mismas consiguieron evidenciar los estragos de la política de seguridad del gobierno de Uribe y las violaciones sistemáticas a los derechos humanos producidas por su ejecución. Con gran visibilidad internacional estas organizaciones posicionaron agendas en torno a cuatro ejes fundamentales: el desplazamiento forzado, documentando y denunciando el caso de más de cinco millones de desplazados en todo el territorio nacional; la violencia contra las mujeres y el que se les utilizara como botín de guerra en el marco del conflicto armado; las violaciones a los derechos sindicales y en específico la aguda e histórica violencia antisindical (López \& Hincapié, 2015), y (tal vez la agenda más importante) la denuncia de las ejecuciones extrajudiciales conocidas como "falsos positivos" en el marco de la política de seguridad del gobierno de Uribe, denuncia que ha trascendido hasta la Corte Penal Internacional gracias al activismo legal transnacional de las ONG. ${ }^{5}$

Como se observa en la tabla 3, el Colectivo de Abogados Alvear Restrepo y la Comisión Colombiana de Juristas fueron de nuevo las organizaciones con mayor presencia debido a su experticia jurídica, mientras que, por su parte, fue creciente la aparición de la Comisión Intereclesial de Justicia y Paz, el GIDH, fCSPP, la Minga y Corporación Jurídica Libertad y Humanidad Vigente, con más de diez presencias.

En la estrategia de activismo legal transnacional, el trabajo coordinado para presentar evidencia sobre la sistematicidad de las violaciones de derechos humanos por parte de agentes estatales en todo el país ha sido crucial, un paradigmático ejemplo de esto fue el de los "falsos positivos" estructurado con información recolectada por las ONG en diferentes regiones de Colombia, y en donde se documentaron la violaciones perpetradas por agentes pertenecientes a diferentes Brigadas del Ejército Nacional bajo un mismo patrón de actuación.

4 Los miembros de las ONG planteaban que el gobierno había entrado en una "batalla estadística" contratando equipos especializados y diluyendo la discusión sobre la victimización. Cuando las ONG exponían las cifras de pobreza y violencia, el presidente Uribe respondía señalando que su actividad era de "demagogos” (Entrevista a Luciano Sanín, exdirector de la Escuela Nacional Sindical. Medellín, Colombia, 2 de septiembre de 2011).

5 Las ONG de derechos humanos lograron documentar la sistematicidad de las ejecuciones extrajudiciales que aumentaron en 200\% durante el gobierno de Álvaro Uribe; estas denuncias han llevado a fuertes pronunciamientos por parte del sistema interamericano y han llegado a la Corte Penal Internacional, la cual reconoció en 2012 que "existe fundamento suficiente" para considerar que dichos actos se relacionan con una política del Estado (Corte Penal Internacional, 2012). 


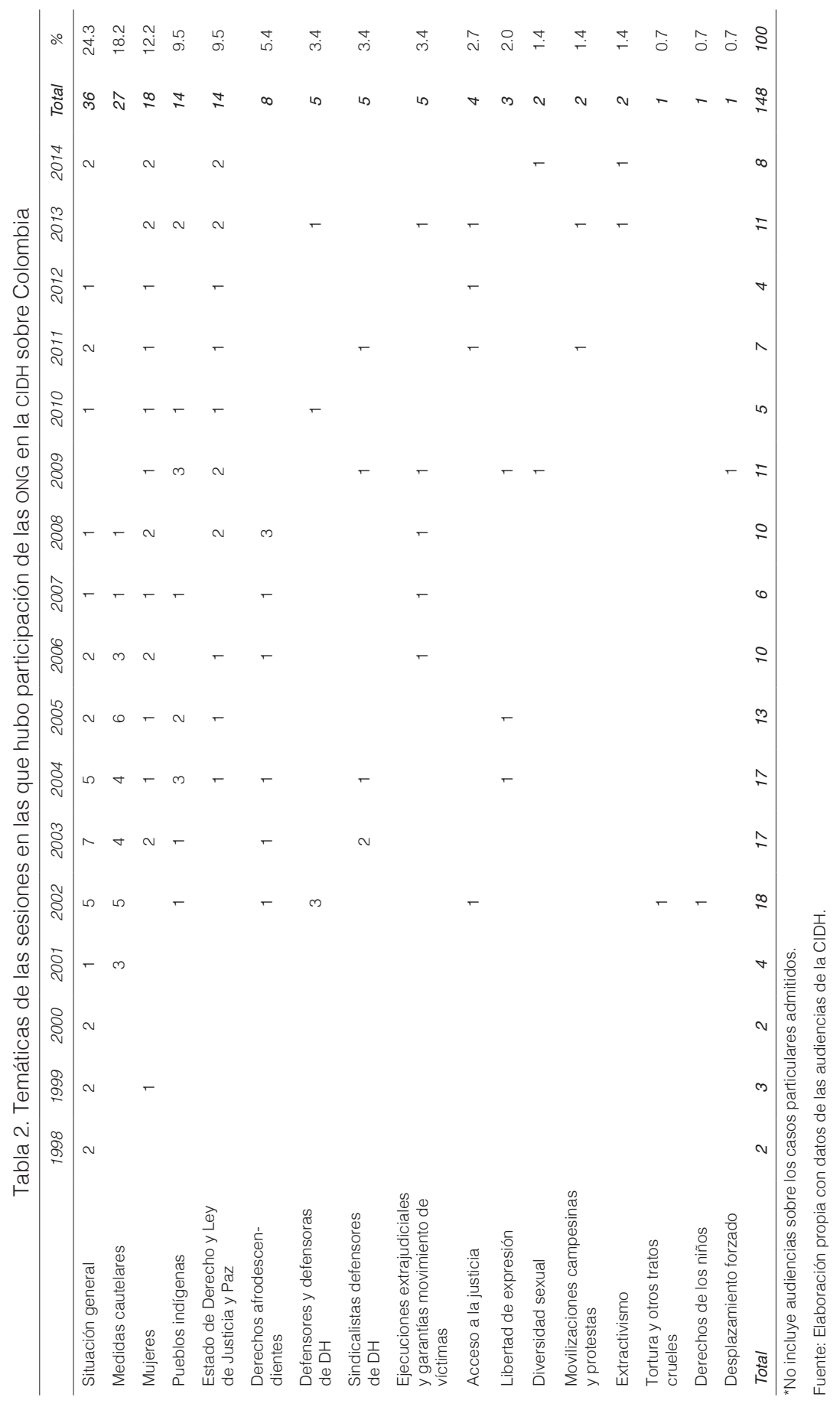

18 - J. A. López Pacheco, S. Hincapié Jiménez | Derechos humanos y activismo legal transnacional. Estrategias de las ong en México y Colombia | Perfiles Latinoamericanos | FLacso México 
Tabla 3. Participación de las ONG en sesiones de la CIDH sobre Colombia, 1998-2014

\begin{tabular}{|c|c|c|c|}
\hline ONG & Total & ONG & Total \\
\hline CCJ & 54 & CCEEU & 3 \\
\hline CAJAR & 54 & Organización Nacional Indígena de Colombia & 3 \\
\hline ClJP & 38 & Red Nacional Mujeres & 2 \\
\hline ONG internacionales (CEJIL, HRW) & 28 & Asociación para la Investigación y Acción Social & 2 \\
\hline Grupo Interdisciplinario de Derechos Humanos & 27 & Ruta Pacífica & 2 \\
\hline Fundación Reiniciar & 26 & Movimiento Nacional de Víctimas de Crímenes de Estado & 2 \\
\hline FCSPP & 24 & País Libre & 1 \\
\hline Otras organizaciones nacionales & 21 & $C D$ & 1 \\
\hline Minga & 21 & Asoc. Prevención Tortura & 1 \\
\hline CJL & 16 & Cabildos Indígenas & 1 \\
\hline SISMA Mujer & 11 & Federación para la Libertad de Prensa & 1 \\
\hline Humanidad Vigente & 8 & Organización Femenina Popular & 1 \\
\hline Asociaciones campesinas & 7 & Nuevo Arcolris & 1 \\
\hline Sindicatos & 7 & $\begin{array}{l}\text { Corporación de Promoción y Defensa de los Derechos } \\
\text { del Pueblo }\end{array}$ & 1 \\
\hline Corporación Jurídica Yira Castro & 5 & CLCP & 1 \\
\hline CPDDH & 4 & Sembrar & 1 \\
\hline $\begin{array}{l}\text { Asociación Nacional de Afrocolombianos } \\
\text { Desplazados }\end{array}$ & 4 & Escuela Nacional Sindical & 1 \\
\hline $\begin{array}{l}\text { Consultoría para los Derechos Humanos y el } \\
\text { Desplazamiento }\end{array}$ & 4 & Consejo Regional Indígena del Cauca & 1 \\
\hline FS & 3 & & \\
\hline
\end{tabular}

Fuente: Elaboración propia con datos de las audiencias de la CIDH.

El trabajo de coordinación de las ONG para la producción de información y conocimiento tuvo en las redes Plataforma Colombiana de Derechos Humanos, Democracia y Desarrollo y la Coordinación Colombia Europa Estados Unidos (CCEEU), los principales espacios de intercambio y centralización de la información para fortalecer sus demandas. La CCEeU, compuesta por más de 170 organizaciones en cinco nodos regionales al interior del país, ha jugado un papel central en la circulación de información sobre las violaciones a los derechos humanos y en la elaboración de informes nacionales sobre temas priorizados por la Asamblea Nacional, información que se circula y socializa al exterior. ${ }^{6}$

Si bien no todas las ONG disponen de los recursos económicos para mantener equipos de trabajo en todas las áreas que permitieran generar la documentación a fondo de los casos de defensa, sí disponen de recursos colectivos de

6 Para la directora de la Organización Femenina Popular el principal elemento movilizador de las plataformas han sido las organizaciones locales y regionales quienes realizan un seguimiento y registro directo de las violaciones ya que: "quien tiene la información tiene el poder, por eso cada ocho días se levanta información y se centraliza en Bogotá". Entrevista, Yolanda Becerra, [Coordinadora de la OFp], Barrancabermeja, Colombia, 2012. 
solidaridad y cooperación, en los que diversas organizaciones y personas aportan en el trabajo según el activismo realizado y la clase de derechos defendidos. Esto permite afirmar que la concentración del activismo legal transnacional de las organizaciones colombianas cuenta con una gran base de apoyo estratégico en la coordinación de diverso tipo de organizaciones movilizadas por la búsqueda de alternativas al conflicto armado y de castigo a la impunidad.

Las sanciones legales transnacionales: reconocimiento de las víctimas del Estado

El activismo legal transnacional de las ONG frente al Sistema Interamericano de Derechos Humanos, en Colombia, tuvo sus principales efectos luego de 2005 cuando se promulgaron diversas condenas contra el Estado (tabla 4). Para los actores colectivos, las sentencias de la Corte representaron un reconocimiento de las demandas históricas de las organizaciones defensoras de derechos humanos y las víctimas, contraria a la estrategia de los diferentes gobiernos de negar el papel del Estado como victimario de las violaciones a los derechos humanos.

Tabla 4. Sentencias condenatorias de la CIDH contra Colombia para 2014

\begin{tabular}{lll}
\hline Sentencias & Año & ONG representante \\
\hline Caso Caballero Delgado y Santana & 1994 & CCJ \\
Caso de Las Palmeras & 2002 & CCJ \\
Caso de los 19 Comerciantes & 2002 & CCJ \\
Caso de la Masacre de Mapiripán & 2005 & CAJAR, CEJIL \\
Caso Gutiérrez Soler & 2005 & CAJAR \\
Caso de la Masacre de Ituango & 2006 & GIDH, CCJ \\
Caso de la Masacre de Pueblo Bello & 2006 & ASFADES, CCJ \\
Caso Escué Zapata & 2007 & Abogados individuales \\
Caso de la Masacre de La Rochela & 2008 & CAJAR \\
Caso Valle Jaramillo y otros & 2009 & GIDH \\
Caso Manuel Cepeda Vargas & 2010 & CAJAR \\
Caso Masacre de Santo Domingo & 2012 & CJS, CAJAR, HV, CIJP \\
Caso Vélez Restrepo y Familiares & 2012 & CCJ \\
Caso de las Comunidades Afrodescendientes Desplazadas de la Cuenca & 2013 & CIJP \\
del Río Cacarica & & \\
Caso Palacio de Justicia & 2014 & CAJAR \\
\hline
\end{tabular}

Fuente: Elaboración propia con datos de los casos de la CIDH.

A partir de la sanción de casos paradigmáticos como la Masacre de Mapiripán, el Salado e Ituango, se dio un reconocimiento jurídico de las múltiples masacres cometidas entre organizaciones criminales y agentes estatales, lo que violaba la 
Convención Americana de Derechos Civiles y Políticos y demás pactos internacionales de derechos humanos.

En ese sentido, como efecto del exitoso activismo legal transnacional, el Estado colombiano ha reconocido en distintas oportunidades su responsabilidad en las violaciones de derechos humanos y ha implementado políticas y programas de derechos humanos en toda la estructura de las organizaciones estatales (incluidas las Fuerzas Armadas), como parte del cumplimiento de algunas de las numerosas recomendaciones hechas por los organismos internacionales.

\section{México: acción colectiva segmentada y fragmentada}

En México, las oNG defensoras de derechos humanos surgieron a finales de los años ochenta con la creación del Centro de Derechos Humanos Fray Francisco de Vitoria (Centro Vitoria) (1984) y la Academia Mexicana de Derechos Humanos (AMDH) (1984), entre otras. Durante este periodo de creación y consolidación, estas ONG tuvieron como objetivos fundamentales emprender procesos de educación popular y divulgación sobre los derechos humanos, pues hasta ese momento el discurso oficial los presentaba como estrategias de intervención por parte de potencias extranjeras, y cumplir una labor de denuncia constante sobre la falta de garantías para el ejercicio de los derechos políticos y la exigencia de mecanismos institucionales que permitieran la efectiva competencia política con alternancia en el poder, como característica imprescindible de las democracias contemporáneas (Aguayo \& Parra, 1997; Durand, 1994).

Luego de que el Partido Revolucionario Institucional (PRI) perdió la Presidencia de la República en el año 2000 y se dio la alternancia - lo cual se ha reconocido como uno de los triunfos más importantes de las demandas apoyadas por las ONG (Estévez, 2008; Treviño, 2004)— hubo cambios en la política federal respecto al reconocimiento del régimen internacional de los derechos humanos que incluyeron que el propio gobierno se autopresentara como "defensor de los derechos humanos" (Maza, 2009). Ello fue de la mano de la especialización de actores en la capital mexicana que orientaron su trabajo a promover reformas institucionales y, al mismo tiempo, hubo un aumento de los cuerpos de expertos (López, 2015).

\section{Actores preponderantes: la segmentación de los demandantes}

Luego de la crisis política de 1988 y la denuncia de fraude electoral tras las elecciones presidenciales que dieron como ganador a Carlos Salinas de Gortari, 
algunas ONG definieron estrategias de demanda con las que pasaron de llevar "causas" a llevar "casos". En otras palabras, se pasó a una mayor especialización en la defensa jurídica de los derechos humanos y a una mayor vinculación con el sistema de protección nacional y supranacional (Estévez, 2007). En esta línea, la creación en 1989 de la Comisión Mexicana de Defensa y Promoción de los Derechos Humanos (CMDPDH) y el Centro de Derechos Humanos Miguel Agustín Pro Juárez (Centro Prodh), inició una estrategia de litigio jurídico que permitió el uso de nuevos recursos.

El mayor protagonismo de las ONG ocurrió en medio de las negociaciones del Tratado de Libre Comercio para América del Norte (TLCAN), negociación que abrió la oportunidad internacional para que las ONG apelaran a las estrategias de presión y cabildeo internacional. En este contexto las ONG buscaron intensificar la presión en los escenarios internacionales, de allí que la Red Nacional de Organismos Civiles de Derechos Humanos Todos los Derechos para Todos (Red TDT) articuló un equipo de trabajo internacional promoviendo, en 1996, la primera visita in situ a México de la Comisión Interamericana.

Luego de esto, las ONG iniciaron una presión ante organismos internacionales que permitió que la defensa de los derechos humanos dejara de ser una actividad desarrollada principalmente en el plano nacional.

Como se observa en la tabla 5, desde 1997 hasta 2013 se han admitido 74 casos en la CIDH, los cuales han sido presentados por actores colectivos variados, entre los que las ONG de derechos humanos nacionales representan aproximadamente el $60 \%$. Dentro de este porcentaje podemos identificar una gran variedad de organizaciones que suman alrededor de diecinueve ong mexicanas. Solo la Comisión Mexicana de Promoción y Defensa de Derechos Humanos, la Asociación de Cristianos contra la Tortura (АСAT) y el Centro de Derechos Humanos Fray Bartolomé de las Casas (Frayba), han tenido tres o más casos admitidos ante la Comisión, lo que suma cerca del 17\% del total.

Este gran conjunto de organizaciones que llevan casos ante la CIDH indica una acción colectiva dispersa y poco especializada que permita la acumulación de experticia de organizaciones nacionales en el activismo legal transnacional; una cuestión que hace más elevados los costos del activismo legal en el plano internacional.

Más significativo resulta el análisis del porcentaje de casos presentados por las ONG internacionales, el cual concentra el $18.9 \%$. Cobra relevancia la concentración por parte del Centro por la Justicia y el Derecho Internacional (CEJIL), ${ }^{7}$

7 El CEjIL es una organización regional que destacados defensores de derechos humanos de Latinoamérica fundaron en 1991 en Caracas, Venezuela, para promover el derecho internacional de los derechos 
ONG que ha llevado once casos admitidos por la CIDH (el 23\% del total), además de que acompaña a oNG nacionales cuando llevan sus casos, lo que revela una tendencia a que la estrategia de activismo legal transnacional se delega en un actor internacional con mayor experticia.

Unido a lo anterior, el elevado porcentaje de actores individuales que llevan casos ante la $\mathrm{CIDH}$, relacionados en particular con garantías de derechos políticos y de acceso a la justicia muestra que las ONG y su acción colectiva no se han logrado posicionar como "bisagras" entre el escenario internacional y el plano nacional para la defensa de los derechos humanos.

Tabla 5. Participación de las ONG en casos admitidos por la CIDH contra México, 19972013

\begin{tabular}{lcc}
\hline ONG & Casos & $\%$ \\
\hline Demandas individuales & 16 & 21.6 \\
Organizaciones Internacionales (CEJIL, TUDH) & 14 & 18.9 \\
Comisión Mexicana de Defensa y Promoción de los Derechos Humanos & 5 & 6.8 \\
Asociación de Cristianos contra la Tortura & 4 & 5.4 \\
Centro Fray Bartolomé de las Casas & 4 & 5.4 \\
Comisión de Solidaridad y Defensa de los Derechos Humanos & 3 & 4.1 \\
Frente Mexicano Pro Derechos Humanos & 3 & 4.1 \\
Nuestras Hijas de Regreso a Casa & 3 & 4.1 \\
Red Ciudadana por la No Violencia & 3 & 4.1 \\
Liga Mexicana por la Defensa de los Derechos Humanos & 2 & 2.7 \\
Organizaciones Indígena Pueblos Tlalpecos & 2 & 2.7 \\
Centro de Derechos Humanos Miguel Agustín Pro Juárez & 2 & 2.7 \\
Tlachinollan. Centro de Derechos Humanos de la Montaña & 2 & 2.7 \\
Comité Abogados por los Derechos Humanos & 2 & 2.7 \\
Asociación Nacional de Abogados Democráticos & 2 & 2.7 \\
Centro de Derechos Humanos Fray Francisco de Vitoria & 1 & 1.4 \\
Centro Regional de Defensa de los Derechos Humanos José María Morelos y Pavón & 1 & 1.4 \\
Tierra y Libertad & 1 & 1.4 \\
Indignación & 1 & 1.4 \\
Centro de Derechos Humanos de las Mujeres & 1 & 1.4 \\
Centro de Derechos Humanos del Paso del Norte & 1 & 1.4 \\
Asociación de Familiares de Detenidos Desaparecidos y Víctimas de violaciones a los Derechos & 1 & 1.4 \\
Humanos en México & 74 & 100.0 \\
Total & 3 \\
\hline
\end{tabular}

Fuente: Elaboración propia con datos de casos de la CIDH. Cabe aclarar que un solo caso puede tener varias ONG como titulares de las demandas. En la tabla se presenta el número de veces que una ONG fue parte titular de un caso, indistintamente de si lo hizo de modo individual o acompañada por otra ONG.

humanos y aprovechar el sistema interamericano para su defensa. Al respecto, véase https://www.cejil .org/cejil/acerca-de-cejil 
Hasta el año 2007 las ong que participaron en el escenario del sistema interamericano se ubicaban en la Ciudad de México, tal sucede con la CMDPDH, el Centro Prodh, el Centro Vitoria, el Centro Nacional de Comunicación Social (CENCOS) y la secretaría ejecutiva de la Red TDT, todas acompañadas por el CEJIL; dicha participación se orientaba a las sesiones generales sobre la situación de derechos humanos en México. Como se observa en la tabla 6, a partir de 2007 el número de audiencias temáticas sobre México en la CIDH creció bastante gracias a las ONG regionales.

El primer hito del activismo jurídico transnacional de las ONG de derechos humanos en México lo protagonizaron las ONG de mujeres del norte del país; las de Chihuahua fueron las primeras en posicionar sesiones temáticas especiales ante la CIDH, como parte de la presión ejercida en la denuncia de los feminicidios y la violencia contra las mujeres en México (Aikin, 2011). Estas ONG locales lograron que la CIDH dedicara al tema seis sesiones especializadas entre los años 2000 y 2006. Pero más allá de esto, dicha presión tuvo efectos concretos en el diseño de políticas públicas nacional, en el reconocimiento del feminicidio como un patrón de actuación particular, en la creación de organismos para la protección de las mujeres, y en la tipificación de dicho delito en el Distrito Federal, entre otras.

Otras organizaciones replicaron la acción colectiva de las ONG de mujeres, y así, a partir de 2008, alcanzaron una importante presencia ante la CIDH consiguiendo sesiones temáticas sobre derechos de los pueblos indígenas, libertad de expresión, derechos de los migrantes en tránsito y protección a los defensores de derechos humanos. Tales sesiones fueron lideradas por ong como Tlachinollan y el Centro Frayba que lograron impulsar y posicionar las agendas locales y regionales.

Los casos denunciados por estas ONG han evidenciado la indefensión y vulnerabilidad de los pueblos indígenas en contextos donde, además de vivir las secuelas del crimen organizado y los abusos de las autoridades estatales, enfrentan la persecución debida al desarrollo de megaproyectos y el imposible acceso a la justicia.

Por su parte, las redes de organizaciones de defensa de los migrantes como Servicio Jesuita de Migrantes en México, Centro Fray Matías de Córdova, la Casa del Migrante (Oaxaca), Centro de Derechos Humanos Fray Juan de Larios (Saltillo), Humanidad sin Frontera, Frontera con Justicia, han construido información que evidencia el drama humanitario de los migrantes indocumentados que pasan por México rumbo a Estados Unidos. ${ }^{8}$

8 Las organizaciones de la sociedad civil solicitaron a la CIDH que la Relatoría sobre Trabajadores Migratorios y Miembros de sus Familias cumpliera una visita in loco a México, para analizar la situación de 


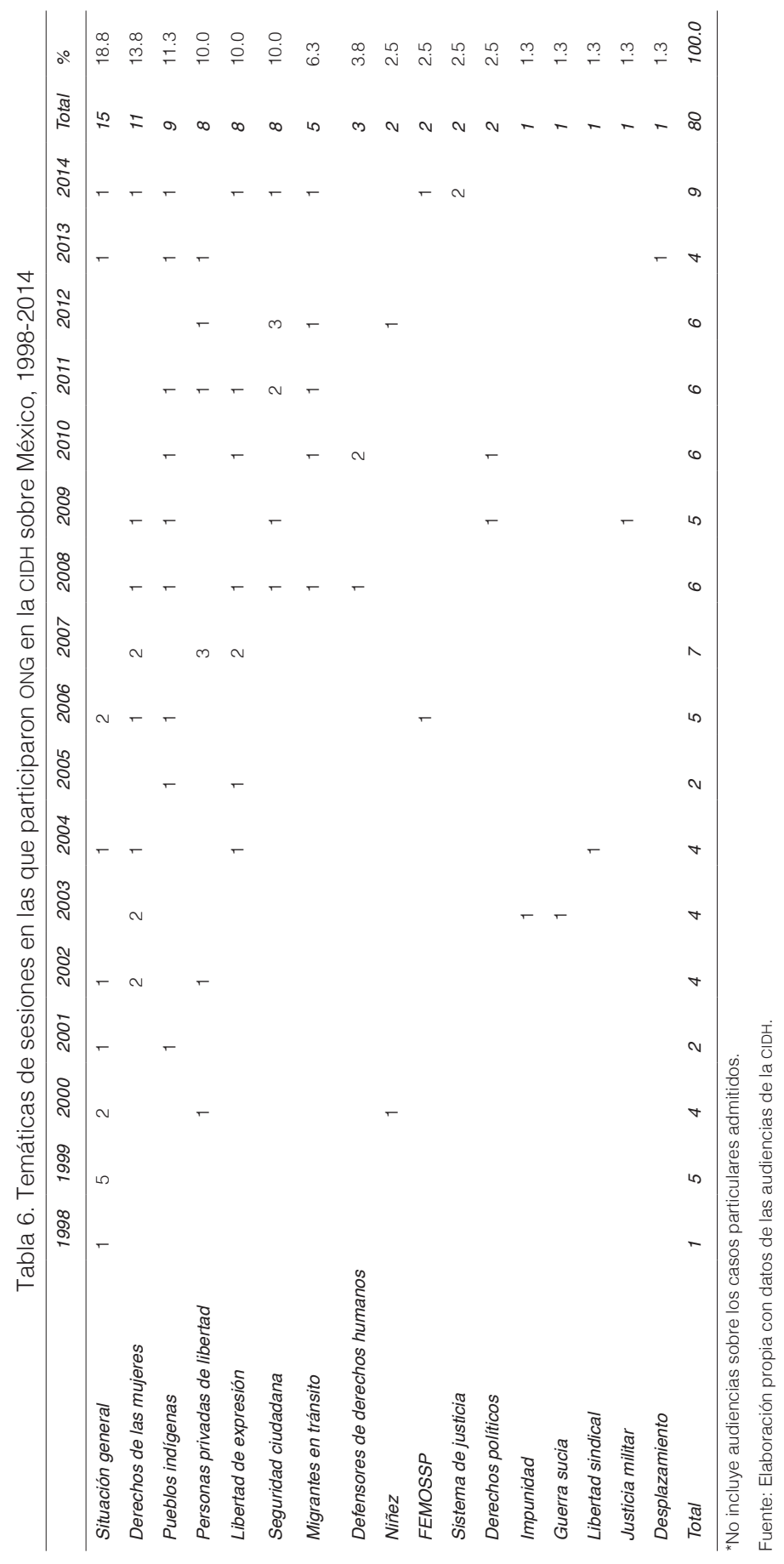


Tabla 7. Participación de las ONG en sesiones de la CIDH sobre México, 1998-2014

\begin{tabular}{|c|c|c|c|}
\hline ONG & Total & ONG & Total \\
\hline CMPDDH & 32 & Fray Matías Córdova & 2 \\
\hline Otras ONG internacionales & 24 & COLEM & 2 \\
\hline CEJIL & 20 & Liga Mexicana & 2 \\
\hline Red TDT & 18 & Fray Juan Larios & 2 \\
\hline ProDH & 18 & GIRE & 2 \\
\hline Organizaciones sociales & 13 & Colectivo de organizaciones michoacanas & 2 \\
\hline Frayba & 8 & AFADEM & 2 \\
\hline Centro Vitoria & 7 & BARCA & 1 \\
\hline Tlachinollan & 7 & Asociación Por lo Justo & 1 \\
\hline FUNDAR & 6 & $\mathrm{AMDH}$ & 1 \\
\hline CENCOS & 6 & Red Defensores Chiapas & 1 \\
\hline Org. ambientalistas & 6 & Asesoría Jurídica Popular & 1 \\
\hline CADHAC & 5 & Red Guerrerense & 1 \\
\hline CEDEHM & 5 & José Morelos y Pavón & 1 \\
\hline IMDDH & 5 & CDC & 1 \\
\hline CCDHNordeste & 5 & Instituto Guerrerense DH & 1 \\
\hline ASILEGAL & 5 & ACUDDEH & 1 \\
\hline CEMDA & 4 & Comité Cerezo & 1 \\
\hline SEREPAZ & 4 & CDHVD & 1 \\
\hline Nuestras Hijas & 4 & Paso Norte & 1 \\
\hline CEDHAPI & 4 & Juan Gerardi & 1 \\
\hline Asociaciones Libertad de Prensa & 4 & Nuestros Desaparecidos Coahuila & 1 \\
\hline IDEHAS & 4 & Justicia y Estado Democrático de Derecho & 1 \\
\hline COSYDHAC & 3 & RSDCIAC & 1 \\
\hline Centro Análisis e Investigación & 3 & FUNDEM & 1 \\
\hline Casa Migrante & 3 & HIJOS México & 1 \\
\hline Debido Proceso Legal & 3 & CAUSA & 1 \\
\hline \multirow[t]{2}{*}{ ACAT } & 2 & $\mathrm{CMDCH}$ & 1 \\
\hline & & LITIGA OLE & 1 \\
\hline
\end{tabular}

Fuente: Elaboración propia con datos de las audiencias de la CIDH.

Como puede observarse, la participación de las ONG en las sesiones de la CIDH sobre México es variada. La más activa es la CMDPDH con 32 participaciones en las ochenta sesiones documentadas. Le siguen el Centro Prodh y la Secretaría de la Red TDT con dieciocho cada una, además de la constante participación del CEJIL.

La amplia participación de ONG locales y regionales se explica por los retos impuestos por el contexto de violencia debido a la expansión del crimen orga-

derechos humanos de los migrantes, lo que sucedió entre el 25 de julio y el 2 de agosto de 2011. El 30 de diciembre del 2013 la ciDH publicó el informe especial Derechos humanos de los migrantes y otras personas en el contexto de la movilidad humana en México (Aikin \& Anaya, 2013). 
nizado y la militarización, ante el cual los actores locales respondieron con la creación de redes de solidaridad y apoyo a las víctimas, y estableciendo nuevas agendas de demanda. Sin embargo, estas últimas no contaron con articulación clara del conjunto de las ong para el activismo legal trasnacional. Para algunos actores esto se ha debido a "disputas por el protagonismo en el ámbito internacional", que manifestaron "problemas de coordinación o de incapacidad para presentar demandas concertadas por todas las organizaciones que logran participar en el Sistema"?

Según Santiago Aguirre, exmiembro de CADHAC y Tlachinollan, y actual subdirector del Centro Prodh:

Las ONG que trabajamos en contextos locales violentos estábamos muy rebasadas con lo que empezó a pasar en México, pero al fin de cuentas reaccionamos, los de Tlachinollan, los de Juárez, los de Saltillo, los de Monterrey [...] Los esfuerzos de articulación nacional de estos temas la verdad es que no contaron con aportes sustantivos de las ong tradicionales en México, si uno mira el Movimiento de Víctimas, no ves ahí a organizaciones con más recursos, pienso que en las organizaciones nacionales hubo una reacción más lenta y no coordinada de lo que estaba pasando. (Entrevista a Santiago Aguirre. Ciudad de México, 8 de abril de 2014).

En ese sentido, las estrategias del activismo legal transnacional que siguieron las ONG en México hasta 2014 no se basaron en procesos de coordinación de los actores, lo que se constituyó en obstáculo para lograr experticia, acumular experiencia, y alcanzar mayor presión y eficacia ante organismos internacionales, lo que, por otra parte, explica el "tutelaje" necesario de las ong internacionales como el CEJIL.

El que los directivos de las grandes organizaciones reconocieran el trabajo solitario de las ONG locales y regionales, al considerar que: "habían sido poco acompañados y poco presentada su crisis de violencia en los escenarios en que nosotros tenemos incidencia" ${ }^{10}$ permitió, especialmente después del caso Ayotzinapa, la articulación de estrategias siguiendo "el modelo de acción colectiva de organizaciones regionales, especialmente del norte del país (Coahuila, Nuevo León, Chihuahua)". ${ }^{11}$

9 Entrevista a Thalía Vega, exintegrante del Centro Prodh, Amnistía Internacional sede México y la CMDpdH. Ciudad de México, 24 de enero de 2014.

10 Entrevista a Santiago Aguirre, subdirector del Centro Prodh, exabogado de Tlachinollan y de CADHAC. Ciudad de México, 8 de abril de 2014.

11 Entrevista a Mariana Mora, coordinadora del Área de Derechos Humanos de Fundar. Ciudad de México, 8 de mayo de 2014 . 
En 2009 y 2010 se dieron las primeras cinco sentencias impulsadas por el activismo legal transnacional de las ONG frente al Estado mexicano como responsable de violaciones a los derechos humanos, lo que generó para este último elevados costos políticos y económicos (tabla 8).

Tabla 8. Sentencias condenatorias de la Corte IDH contra México para 2014

\begin{tabular}{lcl}
\hline Sentencias & Año & ONG defensora \\
\hline Caso Castañeda Gutman & 2008 & Abogados individuales \\
Caso González y otras (“Campo Algodonero") & 2009 & Red Ciudadana de No Violencia y por la Dignidad Humana \\
Caso Radilla Pacheco & 2009 & AFADEM, CMDPDH \\
Caso Fernández Ortega y otros & 2010 & OIPT, Tlachinollan \\
Caso Rosendo Cantú y otra & 2010 & OIPT, Tlachinollan y CentroProdh \\
Caso "Campesinos Ecologistas" & 2010 & CEJIL, Sierra Club, Centro Prodh \\
Caso García Cruz y Sánchez Silvestre & 2013 & CEJIL, SLIEJ \\
\hline
\end{tabular}

Fuente: Elaboración propia a partir de la "Base de datos ONG ante el SIDH".

Las sentencias tuvieron en común que reconocían la responsabilidad estatal en las violaciones a los derechos humanos y que señalaban la necesidad de generar reformas para luchar contra la impunidad. Además de recomendaciones judiciales y administrativas, subrayaron lo expresado por la ONG de derechos humanos respecto al rechazo al uso indebido de la fracción II del artículo 57 del Código de Justicia Militar, favorecedor de la impunidad, calificándolo de violatorio de la obligación de los Estados en cuanto a adecuar la legislación interna a la Convención Americana sobre Derechos Humanos; se ordenaba así la reforma del Código de Justicia Militar en su conjunto (Hincapié, 2013: p. 230). ${ }^{12}$

Como resultado de la presión del activismo legal transnacional, en esta coyuntura de fallos de la CIDH, la Suprema Corte de Justicia de la Nación en el análisis de un caso doméstico, por medio de la Resolución del 12 de julio de 2011, señaló la obligatoriedad para todas las autoridades mexicanas de las sen-

12 En palabras de Sergio García, entonces presidente de la Corte IDH: "el caso que tuvo una proyección mundial fue el caso Radilla y el Rosendo Cantú [...] el caso Radilla y el de las indígenas de Guerrero, eran casos de violación muy grave y directa de seres humanos, desapariciones, violación sexual, investigación errónea, jurisdicción militar, los cuales eran casos sobre los que la Corte ya se había pronunciado en otros países, así que no fue algo novedoso en la jurisdicción, pero fueron condenas a México que generaron la discusión del control de convencionalidad al interior del país". (Entrevista a Sergio García Ramírez, expresidente de la Corte IDH y ex procurador general de México. Ciudad de México, 15 de mayo de 2014). Para un análisis detallado de la jurisprudencia sobre el fuero militar que se incluye en las sentencias de la Corte iDH contra México, véase a Hudlet \& González (2012). 
tencias y la facultad de todos los jueces para realizar un control de convencionalidad aplicando los tratados internacionales de derechos humanos, incluso en perjuicio de la legislación mexicana, lo que generó una nueva estructura de oportunidad jurídica a nivel nacional (scjN, Resolución 12 de julio de 2011). Estos fallos y sus efectos reforzaron la legitimidad de las demandas de las ONG y reafirma el escenario internacional como un espacio fundamental de movilización para las ONG defensoras de derechos humanos.

\section{Conclusiones}

El sistema interamericano de derechos humanos se ha convertido en América Latina (y cada vez más) en un escenario de demanda y movilización hacia el cual las ONG de derechos humanos orientan sus acciones, buscando presionar e impactar en el respeto de los derechos humanos en sus respectivos países. Al sistematizar y analizar la información proporcionada por el sistema interamericano de derechos humanos pudimos establecer que México y Colombia son los dos países latinoamericanos de los cuales más denuncias han sido presentadas con diferentes resultados.

Con la construcción de una base de información empírica sobre el activismo de las ONG colombianas y mexicanas ante el sistema interamericano de derechos humanos, y la realización de una rigurosa sistematización de información primaria, identificamos las estrategias de acción colectiva seguidas por las ONG en cada uno de estos países. Explicamos cómo las estrategias de las ONG en el plano internacional se relacionan con las interacciones y formas de articulación en los contextos nacionales, lo que determina el activismo que se realiza frente a las oportunidades legales transnacionales.

Tabla 9. Comparación de las estrategias de activismo legal transnacional en Colombia y México

\begin{tabular}{|c|c|c|}
\hline & Colombia & México \\
\hline $\begin{array}{l}\text { Actores } \\
\text { preponderantes }\end{array}$ & $\begin{array}{l}\text { Concentración en organizaciones expertas } \\
\text { en el activismo jurídico: CCJ, CAJAR, CIJP, } \\
\text { GIDH, ASFADDES, Humanidad Vigente y } \\
\text { la Minga. }\end{array}$ & $\begin{array}{l}\text { Segmentación y gran dispersión de las } \\
\text { organizaciones no gubernamentales } \\
\text { nacionales que presentan casos admitidos. } \\
\text { Prevalencia de ONG de carácter internacional. }\end{array}$ \\
\hline $\begin{array}{l}\text { Presión en la } \\
\text { CIDH }\end{array}$ & $\begin{array}{l}\text { División del trabajo para el activismo } \\
\text { jurídico. } \\
\text { Participación amplia, diversa y coordinada; } \\
\text { la coordinación se basa en la producción de } \\
\text { información creíble y confiable de las ONG } \\
\text { que acuden a las sesiones temáticas y no } \\
\text { son expertas en la defensa jurídica. }\end{array}$ & $\begin{array}{l}\text { Pluralidad y fragmentación en la participación } \\
\text { de las ONG nacionales. Las agendas presen- } \\
\text { tadas con más efectividad se circunscriben a } \\
\text { trayectorias de acción colectiva local como en } \\
\text { el caso de los feminicidios; ausencia de coordi- } \\
\text { nación estratégica para socializar información } \\
\text { creíble de la crisis de derechos humanos. }\end{array}$ \\
\hline Sanciones legales & $\begin{array}{l}15 \text { condenas con la representación de } 5 \\
\text { ONG. }\end{array}$ & $\begin{array}{l}7 \text { condenas con la representación de } 10 \\
\text { actores colectivos. }\end{array}$ \\
\hline
\end{tabular}

Fuente: Elaboración propia. 
Identificamos dos tipos de estrategias colectivas para el activismo legal transnacional: primero, una estrategia de concentración-coordinación de demandas en el caso colombiano, en la cual existe una consolidación de las organizaciones nacionales para canalizar la presión ante el sistema interamericano y un proceso de articulación en el contexto nacional para apoyar dichas demandas por parte de un conjunto amplio de ONG en las regiones del país. Segundo, una estrategia de segmentación-fragmentación de las demandas en el caso mexicano, en la que hay una gran variedad de ONG nacionales y locales que presentan casos, sin procesos consolidados de coordinación, concertación o división del trabajo con las demás organizaciones para hacer más efectiva la acción colectiva.

En Colombia la concentración de la experticia de un pequeño conjunto de ONG se complementa con la activación de denuncias y socialización de información creíble que otro amplio conjunto de organizaciones presentan ante la CIDH como apoyo en el proceso del activismo legal transnacional, en amplios procesos de concertación y cooperación conjunta. En el caso mexicano, la ausencia de mecanismos claros de coordinación y cooperación entre las organizaciones para emprender el activismo legal transnacional, explica las dificultades para acumular acervos de información confiable producida por dichas organizaciones y con la que se pudiera documentar los casos y contrastar con las cifras oficiales. Tal fragmentación también impide la acumulación colectiva de experiencia y aprendizaje, necesaria para hacer de la acción colectiva de las ONG de derechos humanos mexicanas las "bisagras" para el activismo jurídico entre los escenarios nacionales e internacionales, sin depender del tutelaje o acompañamiento de actores internacionales. Sin embargo, esta tendencia a la fragmentación en el caso mexicano se ha venido superando, sobre todo en el último año, tras los sucesos de Ayotzinapa, lo que ha dado paso a una mucho más clara articulación.

En un contexto en el que cada vez son mayores las oportunidades de enjuiciamiento y castigo de las violaciones graves de los derechos humanos y donde nuevos organismos como la Corte Penal Internacional toman mayor relevancia (Sikkink, 2013), las ONG de derechos humanos tienen grandes retos y posibilidades de hacer del activismo legal transnacional una vía de presión efectiva para conseguir transformaciones estatales que conduzcan a un mayor respeto por los derechos humanos en la región.

\section{Referencias}

Aguayo, S. \& Parra, L. (1997). Las organizaciones no gubernamentales de derechos humanos en México: entre la democracia participativa y la electoral. México: Academia Mexicana de Derechos Humanos. 
Aikin, O. (2011). Activismo social transnacional. Un análisis en torno a los feminicidios en Ciudad Juárez. México: ITESo/COLEF/UACJ.

Aikin, O. \& Anaya, A. (2013). Crisis de derechos humanos de las personas migrantes en tránsito por México: redes y presión transnacional. Foro Internacional, 53(1), 143-181.

Anaya, A. (2012). El pais bajo presión. Debatiendo el papel del escrutinio internacional de derechos humanos sobre México. México: CiDE.

Ansolabehere, K. (2010). Los derechos humanos en los estudios sociojurídicos. En Estévez, A. \& Vázquez, D. (Coords.). Los derechos humanos en las ciencias sociales: una perspectiva multidisciplinaria (pp. 19-39). México: Flacso México/Cisan-unam.

Bob, C. (2010). The International Struggle for New Human Rights. Philadelphia: University of Pennsylvania Press.

Cárdenas, S. (2007). Conflict and Compliance: State Responses to International Human Rights Pressures. Philadelphia: University of Pennsylvania Press.

Comisión Interamericana de Derechos Humanos (2015). Observaciones preliminares de la Visita in Loco de la CIDH a México, 2 de octubre, Anexo Comunicado de Prensa-Observaciones preliminares. Recuperado de http://www.oas.org/es/cidh/prensa/comunicados/2015/112A.asp

Comisión Interamericana de Derechos Humanos (2012). Informe Anual 2012. Washington: CIDH.

Comisión de Investigación de los Sucesos Violentos de Trujillo (1995). Caso 11.007 de la Comisión Interamericana de Derechos Humanos. Informe Final. Bogotá: Consejería Presidencial para los Derechos Humanos de la República de Colombia.

Corte Penal Internacional (2012). Situación en Colombia. Reporte Intermedio. Recuperado de http://www.icc-cpi.int/NR/rdonlyres/3D3055BD-16E2-4C83-BA85-35BCFD2A7922 /285202/OTP2012035032COLResumenEjecutivodelRe porteIntermed.PDF

Durand, V. (1994). El movimiento por el respeto de los derechos humanos y la transición política. En La construcción de la democracia en México. Movimientos sociales y ciudadanía. México. Siglo XXI.

Estévez, A. (2008). Human Rights and Free Trade in Mexico: A Discursive and Sociopolitical Perspective. Nueva York: Palgrave Macmillan.

Estévez, A. (2007). Transición a la democracia y derechos humanos en México: la pérdida de integralidad en el discurso. Andamios, 3(6), 7-32. 
Ferrajoli, L. (2007). Los fundamentos de los derechos fundamentales. Madrid: Trotta.

Gallón, G. (2007). Simposio una revisión crítica del Sistema Interamericano de Derechos Humanos: Pasado, Presente y Futuro. Anuario de Derechos Humanos 2007. Santiago de Chile: Universidad de Chile.

Garth, B. (2008). The Globalization of the Law. En The Oxford Handbook of Law and Politics (pp. 231-255). Oxford: Oxford University Press.

González, F. (2010). Las medidas urgentes en el Sistema Interamericano de Derechos Humanos. Sur. Revista Internacional de Derechos Humanos, 7(13), 51-73.

Haddad, H. (2012). Judicial Institution Builders: NGOs and International Human Rights Courts. Journal of Human Rights, 11, 126-149.

Held, D. (1997). La democracia y el orden global. Del estado moderno al gobierno cosmopolita. Barcelona: Paidós.

Hincapié Jiménez, S. (2013). Órdenes yuxtapuestos. Dinámicas contenciosas, reformas estatales y crimen organizado en México y Colombia 1982-2012. Tesis de doctorado. Flacso México: México.

Hudlet, K. \& González, D. (2012). Los efectos de la incidencia internacional de las organizaciones de la sociedad civil: el caso de la Corte Interamericana de Derechos Humanos y el Fuero Militar en México. El Cotidiano, (172), 136-152.

Jaramillo, J. \& Castro, L. (2008). La ejecución interna de las decisiones de los órganos internacionales de protección de los derechos humanos. El caso colombiano. En Rengifo, J. (Ed.). Derecho internacional de los derechos humanos y sistemas internos de protección y reparación (pp. 65-87). Bogotá: Ministerio de Relaciones Exteriores/Universidad Nacional de Colombia.

Jetschke, A. \& Liese, A. (2013). The Power of Human Rights a Decade After: From Euphoria to Contestation? En The Persistent Power of Human Rights: From Commitment to Compliance (pp. 26-42). Cambridge: Cambridge University Press.

Keck, M. \& Sikkink, K. (2000). Activistas sin fronteras. Redes de defensa en politica internacional. México: Siglo xxI.

Ley, S. (2012, 28 de noviembre). Conteos comparados de la violencia en América Latina. Letras Libres. Recuperado de http://www.letraslibres.com/blogs/polifonia/conteos-comparados -de-la-violencia -en-america-latina 
López Pacheco, J. A. (2015, noviembre-diciembre). El campo de las ONGs de derechos humanos en México: recursos y agendas. El Cotidiano, 30(194).

López Pacheco, J. A. (2013). Accountability social, organizaciones no gubernamentales de derechos humanos y conflicto político en Colombia, 2002-2010. Revista Mexicana de Sociología, 75(2), 55-286.

López Pacheco, J. A. (2012). Las organizaciones no gubernamentales de derechos humanos en la democracia. Aproximaciones para el estudio de la politización de los derechos humanos en Colombia. Estudios Politicos, (41), 103-123.

López Pacheco, J. A. \& Hincapié Jiménez, S. (2015, octubre-diciembre). De la movilización tradicional a las redes de presión transnacional. Violencia antisindical y derechos humanos en Colombia. Foro Internacional, Lv4(222), 1082-1114

MacDowell, C. (2007). El activismo legal transnacional y el Estado: reflexiones sobre los casos contra Brasil en el marco de la Comisión Interamericana de Derechos Humanos. Sur. Revista Internacional de Derechos Humanos, 4(7), 26-57.

Maza, E. (2009). Derechos humanos: México retórica sin compromiso. México: Flacso México.

McCann, M. (2006). Law and Social Movements: Contemporary Perspectives. Annual Review of Law and Social Science, 2(2), 17-38.

Ramírez, N. (2009). Redes transnacionales de defensa. El caso reciente del Estado colombiano en el contexto de la intervención de la Corte Interamericana de Derechos Humanos. Colombia Internacional, (69), 182-203.

Risse, T., Ropp, S. \& Sikkink, K. (2013). The Persistent Power of Human Rights: From Commitment to Compliance. Cambridge: Cambridge University Press.

Risse, T., Ropp, S. \& Sikkink, K. (1999). The Power of Human Rights: International Norms and Domestic Change. Cambridge: Cambridge University Press.

Romero, F. (2001). El movimiento de derechos humanos en Colombia. En Archila, M. \& Pardo, M. (Eds.). Movimientos sociales, Estado y democracia en Colombia (pp. 441-472). Bogotá: Universidad Nacional/ICANH.

Sikkink, K. (2013). La cascada de la justicia. Cómo los juicios de lesa humanidad están cambiando el mundo de la política. Buenos Aires: Gedisa. 
Sikkink, K. (2005). The Transnational Dimension of the Judicialization of Politics in Latin America. En Sieder, R., Schjolden, L. \& Angell, A. (Eds.). The Judicialization of Politics in Latin America. Nueva York: Palgrave Macmillan.

Simmons, B. (2009). Mobilizing for Human Rights: International Law in Domestic Politics. Cambridge: Cambridge University Press.

Tate, W. (2007). Counting the Dead. The Culture and Politics of Human Rights Activism in Colombia. Berkeley: University of California Press.

Treviño, J. (2004). Las ong de derechos humanos y la redefinición de la soberanía del Estado mexicano. Foro Internacional, XLIV (3), 509-539.

Tsutsui, K., Whitlinger, C. \& Alwyn, L. (2012). International Human Rights Law and Social Movements: States' Resistance and Civil Society's Insistence, Annual Review of Law and Social Science, 8, 367-396.

Recibido el 13 de abril de 2015. Aceptado el 22 de noviembre de 2015. 